\title{
Focus fronting and the syntax-semantics interface
}

\author{
Valentina Bianchi
}

\section{Introduction}

An important question for the cartographic approach is why the functional categories appear in the precise order that they do. A related and equally important question is whether the functional hierarchy is equally rich in all phases. Although parallelisms have been suggested between CP and DP (e.g. Giusti 2006) and between CP and vP (e.g. Belletti 2004), there is one clear exception: the topmost layer of the CP field, Rizzi's (1997) Force, is unique to this phase; in certain analyses, Force is not even shared by all CP phases.

Haegeman (2004) proposed that the lack of Force implies the impoverishment of the left periphery of a clause: she pointed out that in English, 'central' adverbial clauses - arguably lacking illocutionary force - cannot host Argument Fronting/Topicalization. Building on this proposal, Bianchi \& Frascarelli (2010) argued that the articulation of the left periphery of a clause is constrained by the status of that clause at the interface: in particular, those projections whose interpretive import contributes to updating the conversational context can be activated only if the host clause is endowed with Force and conveys a conversational move:

(1) Interface Root Restriction (Bianchi \& Frascarelli 2010)

Information Structure (IS) phenomena that affect the conversational dynamics must occur in clauses endowed with illocutionary Force.

In this paper, I apply this hypothesis to the analysis of focus fronting in Italian, and I show that it can explain the restricted syntactic distribution of this structure.

\section{Focus Fronting in Italian}


Descriptively, focus fronting is a structure in which the constituent bearing the most prominent pitch accent appears in a left-peripheral position:

(2) [Lucía] hanno licenziato _.

Lucy (they) have fired

'It is Lucy who they fired.'

In the cartographic framework, this obtains by movement of the fronted constituent to a Focus projection in the CP domain. ${ }^{1}$

Rizzi (1997) and Belletti (2004) argue that in Italian, fronting is not allowed when the constituent bears new information focus (i.e. when it matches the interrogative phrase in the current question under discussion, e.g., in (2), the question 'Who did they fire?'), ${ }^{2}$ fronting is instead associated with a 'contrastive' interpretation. This comes in two flavours, as described in the following subsections.

\subsection{The corrective import}

First, focus fronting is commonly found in corrective contexts, where a speaker B rejects a previous assertion by a speaker A and asserts a partly different proposition:

(3) A: Gianni ha licenziato Silvia.

John has fired Sylvia

'John fired Sylvia.'

\footnotetext{
${ }^{1}$ Samek-Lodovici $(2006, \S 4)$ proposes a different analysis in terms of right-dislocation of the post-focal material.

${ }^{2}$ In Belletti (2004), new information focus is licensed in the periphery of the vP phase. In the following discussion, I will leave aside new information focus.
} 
B: [Lucia] $e_{2}$ ha licenziato _, (non Silvia). ${ }^{3}$

Lucy (he) has fired, (not Sylvia).

'It is Lucy who he fired (not Sylvia).'

The focus structure in $(3 \mathrm{~B})$ - with narrow focus on the fronted direct object - establishes a specific connection with (3A): (3A) expresses the proposition fire(john, sylvia), (3B) the proposition fire(john, lucy), and the focus alternatives of (3B), defined at the propositional level, are of the form $\{$ fire(john, $\left.\mathrm{x}) \mid \mathrm{x} \in \mathrm{D}_{\mathrm{e}}\right\}$ (ignoring tense; $\mathrm{x}$ varies over individuals, john is the value assigned to the null subject by the assignment function). The proposition expressed by (3A) is a member of the set of focus alternatives of (3B), ${ }^{4}$ giving rise to a contrast across utterances. ${ }^{5}$ The corrective import can thus be characterized as the presupposition that the corrective claim is logically incompatible with a previously asserted alternative in the context of interpretation - i.e., the corrective claim and the alternative are incompatible descriptions of one and the same event (van Leusen 2004).

What is the effect of the corrective import on the conversational dynamics? Following Stalnaker (1978), the conversational community shares a body of information which is mutually taken to be accepted by all the participants: the common ground (CG: a set of propositions). When a speaker asserts a sentence, he proposes to his audience to add the asserted proposition to the CG;

\footnotetext{
${ }^{3}$ Focus fronting in (3B) is apparently optional: I refer again to Bianchi \& Bocci (2012) for discussion.

${ }^{4}$ For simplicity, I adopt alternative semantics for focus (Rooth 1992).

${ }^{5}$ Correction targets only the material corresponding to the focus part, whereas the rest of the clause is validated. The corrected part of the incompatible alternative may be overtly denied in an optional negative coda, cf. (3B).
} 
if the assertion is not rejected by anyone, the proposition is entered in the $\mathrm{CG}$, thus becoming shared information. Now, since no update can introduce an inconsistency, the corrective claim (3B) effectively implies the rejection of A's assertion (the incompatible alternative). Thus, focus fronting associated with the corrective import implements a complex conversational move; ${ }^{6}$ by the IRR, we expect it to be restricted to clauses endowed with illocutionary Force.

\subsection{The mirative import}

Italian focus fronting may also be associated with a radically different type of import, which can be intuitively characterized as emphatic:

(4) (Non posso crederci!) [Un anello di diamanti] $e_{2} l_{3}$ ha regalato!

(I) not can believe-it! A diamond ring (he) to-her has given

'(I can't believe it!) He gave her a diamond ring!'

This kind of fronting has been taken to convey the implicature that the proffered information is unexpected or suprising (Abeillé et al. 2008, Zimmermann 2007). Cruschina (2012) suggests a connection with the category of mirativity, whereby a speaker conveys that the information he is asserting is recently acquired and not yet integrated in her system of beliefs (De Lancey 1997): accordingly, I will label this type of import 'mirative import'.

I follow Zimmermann (2007) in assuming that in cases like (4), the fronted direct object is the focus even though the whole clause may be uttered out of the blue, and therefore, narrow focus on the direct object is not licensed by question-answer congruence. But then, what licenses this narrow focus?

${ }^{6}$ In Italian contrastive focus lacking a corrective import disallows focus fronting (see Bianchi \& Bocci 2012 for experimental evidence and for discussion). 
The answer is that this focus structure allows us to generate the alternatives that we need in order to interpret the mirative import: the latter conveys that the asserted proposition is unexpected as compared to some distinct focus alternative(s). In (4), the alternatives vary in the position of the direct object, and are of the form 'John gave Mary Q': $Q([\lambda x$. give (john, $\mathrm{x}, \mathrm{mary})])(\mathrm{Q}$ is a quantifier, the lambda term is the quantifier's scope, john and mary are the values assigned to the subject and indirect object pronouns by the assignment function).

But what does it mean for a proposition $\mathrm{p}$ to be unexpected w.r.t. another proposition q? Quite simply, it means that $\mathrm{p}$ is less likely than $\mathrm{q}$ in view of the normal course of events (Grosz 2011). Comparative likelihood can be defined in Kratzer's $(1991,2012)$ analysis of modality within possible world semantics. In intuitive terms, there is an infinite number of possible ways that the world may be: each one can be thought of as a possible world. When interpreting natural language sentences, however, we do not take into account all the possible worlds, but only a subset of them: for instance, the worlds that are compatible with our beliefs. Such a subset of worlds constitutes a modal base, and provides the first parameter for interpretation.

The second parameter is what Kratzer calls an ordering source: this is a set of propositions defining an ideal, e.g. a buletic ideal. The worlds in the modal base are then ranked according to how close they come to this ideal: for any world w, the more the propositions of the ordering source which are true in $\mathrm{w}$, the closer $\mathrm{w}$ is to the ideal. For illustration, assume an ordering source consisting of the two propositions (a) that noone suffers hunger and (b) that there are no wars: the worlds of the modal base in which both propositions are true are closer to the ideal than the worlds in which only one of them is true, and these, in turn, are closer than the worlds in which neither proposition is true. 
The ranking of the worlds in the modal base allows us to define a relation of comparative possibility between two propositions $p$ and $q: p$ is a better possibility than $q$ if and only if (a) within the modal base, no possible world in which $p$ is false and $q$ is true is closer to the ideal than all the worlds in which $p$ is true and $q$ is false, and (b) the reverse does not hold (Kratzer 2012, ch.3). Intuitively, this ensures that within the modal base, some $p$-world is closer to the ideal than all the $q$-worlds.

Comparative likelihood is a particular flavour of comparative possibility, determined by an informative modal base and a stereotypical ordering source: the latter is a set of propositions representing what constitutes 'the normal course of events'.

With this background, we can define the mirative import as follows: ${ }^{8}$

(5) Mirative import: There is at least one alternative proposition which is more likely than the asserted proposition w.r.t. a contextually relevant modal base and a stereotypical ordering source.

In our example (4), the mirative import conveys that there is at least one alternative proposition of the form $\mathrm{Q}([\lambda \mathrm{x}$. give (john, $\mathrm{x}, \mathbf{m a r y})])$ which is more likely that the proposition that John gave Mary a diamond ring. Note that, contrary to the corrective import, there need not be any salient proposition in the context, but the existence of more likely alternatives can be inferred from general world knowledge.

7 The information state defining the modal base and the set of propositions representing the 'normal course of event' actually depend on the world/circumstance of evaluation; for simplicity, I disregard this dependency in my informal exposition.

${ }^{8}$ For reasons of space, I cannot compare (5) to Grosz's original formulation; I refer the reader to Grosz (2011, especially $§ 4.1 .2)$. 
The mirative import defined in (5) is not just the expression of a subjective evaluation, but it is in fact a proposal to negotiate a shared evaluation with the hearer(s). In fact, it is possible for participant B to reject the mirative import associated with participant A's assertion, while accepting its truth-conditional content:

(6) A: Pensa, i miei genitori, [una macchina] mi hanno regalato _!

Think.IMP, my parents, a car me.CL have.3PL given

'Guess what, my parents bought me a car!'

B: Be', che c'è di strano?

well, what is there of strange (about that)?

'Well, what's strange about that?'

This separation shows that the mirative import belongs in a dimension of meaning which is separate from the truth-conditional content of the assertion (it is a kind of expressive meaning, in the sense of Kratzer 2004). On the one hand, the asserted truth-conditional content is proposed to be included in the CG; on the other hand, the mirative import is used by the speaker to propose a shared evaluation; each of these two updates may be separately rejected by the hearer(s).

But if the mirative import is not a purely subjective evaluation, which modal parameters is it based on? Consider first the modal base. Recall that the participants to a conversation share a common ground (CG) of presupposed propositions. The $\mathrm{CG}$ determines a set of worlds (the context set, CS) in which all the presupposed propositions are true. When a speaker asserts a sentence, and her assertion is accepted, the expressed proposition is added to the CG; this will in turn update the CS by discarding from it those possible worlds in which the proposition is false (Stalnaker 1978). We can then assume that the modal base for the interpretation of the mirative import corresponds to the CS, crucially prior to the acceptance of the assertion that conveys the 
mirative import. ${ }^{9}$ Moreover, the stereotypical ordering source is typically shared by the conversational participants (Kratzer 2012): namely, the participants share a common view on what constitutes the normal course of events. Thus, both the modal parameters are part of the discourse context.

The upshot of this discussion is that in the course of a conversation, the participants cooperatively build up not only a shared body of information, but also a shared evaluative perspective. Accordingly, the discourse context must include, besides the informative CG, an additional and separate evaluative component, where the expressed evaluations are recorded. ${ }^{10}$ If the mirative import has a direct impact on the evaluative component of the discourse context, we expect that instances of focus fronting with a mirative flavour will fall under the IRR.

\footnotetext{
${ }^{9}$ After the assertion is accepted, the asserted proposition $\mathrm{p}_{0}$ is true in all the worlds of the updated CS, and then by (5), no alternative proposition $\mathrm{p}_{\mathrm{f}}$ can be a better possibility than $\mathrm{p}_{0}$ in CS. This is because for any alternative proposition $\mathrm{p}_{\mathrm{f}}$ to be a better possibility than the asserted proposition $\mathrm{p}_{\mathrm{o}}$, in the modal base there must be at least one possible world $\mathrm{u}$ in which $\mathrm{p}_{\mathrm{f}}$ is true and $p_{0}$ is false which is ranked higher than all the worlds in which $\mathrm{p}_{0}$ is true and $\mathrm{p}_{\mathrm{f}}$ is false. However, if $\mathrm{p}_{0}$ is true in all the worlds of the modal base, there can be no such a world $\mathrm{u}$.

${ }^{10}$ An explicit definition of the evaluative component is beyond the limits of this paper. Minimally, it will contain (a) the ordering sources that are exploited in the course of the conversation (each one a set of propositions defining an ordering of the worlds of the modal base), (b) any evaluative proposition that has been expressed as an individual commitment of a single participant (but not accepted by the other participants) or that has been jointly accepted by all participants as a shared evaluation.
} 


\section{Focus fronting as a root phenomenon}

To recapitulate, I have argued that the interpretive import associated with Italian focus fronting either corrective or mirative - updates the conversational context, and by the IRR (1), this structure should only be licensed in clauses endowed with illocutionary Force. This requirement is uncontroversially satisfied in main clauses. However, Hooper\&Thompson (1973) argued certain complement clauses behave like main clauses in being exceptionally endowed with assertive force, and in allowing for 'root transformations'. ${ }^{11}$ After various reformulations (Gärtner 2002, Meinunger 2004 a.o.) and a critical assessment (Bentzen et al. 2007), this idea has been recently revived by Dayal\&Grimshaw (2009), who analyse such complement clauses as 'quasi-subordinate': although syntactically embedded, they are discourse-active in that they bear context update potential.

Let us consider in this respect the distribution of Italian focus fronting. We can see that it is allowed not only in main clauses (cf. (3B) and (4)), but also in complements to non-factive verbs of saying and opinion: this holds both under the corrective interpretation (7B)-(8B) and under the mirative interpretation (9).

(7) A: Maria ha detto [che le hanno regalato un braccialetto].

Mary has said that her.CL have.3PL given a bracelet.

'Mary said that they gave her a bracelet.'

${ }^{11}$ Haegeman (2004) extended Hooper \& Thompson's insight to analyse 'peripheral' adverbial clauses, which also allow for root transformations. In later work, she abandoned this approach in favour of an analysis based on intervention effects (see Haegeman 2010). Miyagawa (2012) proposes a mixed approach, in which some root transformations require the presence of a 'speech act layer' in the left periphery. 
B: No, $e$ ha detto [che [un anello] $e$ le hanno regalato _].

no, (she) has said that a ring (he) her .CL have.3PL given

'No, she said that they gave her a ring.'

(8) A: Maria pensa [che affideranno l'incarico a lei.]

Mary thinks that (they) will-assign the task to her

'Mary believes that they will assign that task to her.'

B: No, lei pensa [che [a te] lo affideranno _].

no, she thinks that to you (they) it will-assign

'No, she believes that they will assign it to you.'

(9) $e$ sostiene addirittura [che [un anello di diamanti] le hanno regalato _!]

(she) claims even that a diamond ring (they) her.CL have given

'She even claims that they gave her a diamond ring!'

As Hooper\&Thompson (1973) noted, this distribution changes dramatically if the matrix clause contains a negation: compare (7B)-(8B) to (10B) and (9) to (11).

(10) A: Maria non pensa [che affideranno l'incarico a lei.]

Mary not thinks that (they) will-assign the task to her

'Mary doesn't believe that they will assign that task to her.'

B: * Veramente lei non pensa [che [a te] lo affideranno _].

Actually she not thinks that to you (they) it.CL will-assign

(11) * pro non sostiene [che [un anello di diamanti] le hanno regalato _ !]

(she) not claims that a diamond ring (they) her.CL have given

There are two possible views of embedded focus fronting as in (7)-(9). A first possibility is that the focus element moves covertly to the Focus projection in the left periphery of the root clause, 
in order to comply with the IRR at the syntax-semantics interface. From this perspective, the interference of negation in (10B) and (11) looks like an intervention effect: the covert movement of the focus constituent would be an instance of $\mathrm{A}^{\prime}$-movement, so it is conceivable that negation, an $\mathrm{A}^{\prime}$-operator, creates an intervention effect, as schematically represented in (12).

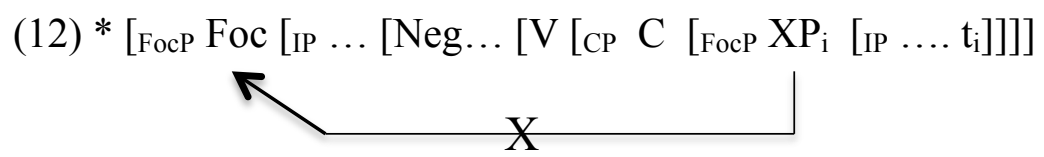

A second logical possibility is that in (7)-(9) the complement clause itself is endowed with illocutionary Force, and hence, focus fronting complies with the IRR within the embedded left periphery: this view is consonant with Hooper\&Thompson (1973) and Dayal\&Grimshaw (2009), but it raises the question of the role of the matrix clause negation in (10B)-(11).

Hooper\&Thompson suggested that negation in the matrix clause deprives the complement clause of assertive force. This insight can be reformulated within the stalnakerian picture of context update. Recall that in this approach, assertive force is a particular type of context update potential: when a speaker asserts a sentence, he proposes to his audience to add the asserted proposition to the CG, and to 'shrink' the CS by discarding those possible worlds in which the proposition is false. However, Gunlogson (2003) and Farkas\&Bruce (2010) have stressed that in addition to its impact on the CS, an assertion also commits the speaker to the truth of the expressed proposition. This important qualification allows us to characterize in a more precise way the status of a discourse-active complement clause selected by a verb of saying or opinion, as in (7B)-(8B) and (9): the speaker proposes that the proposition expressed by the complement clause be added to the CG, but instead of committing herself to the truth of this proposition, she 
commits the subject of the matrix clause (the attitude holder, e.g. Mary in (7)-(8)). Under this view, the embedded clause is endowed with context update potential. ${ }^{12}$

I propose that this 'indirect update' is allowed under a compatibility presupposition: the participants presuppose that Mary's belief state does not support any proposition that is logically inconsistent with the CG. Note that an attitude verb like say or believe implies that the proposition expressed by the complement clause is true in all the worlds that are compatible with Mary's beliefs (a doxastic modal base): therefore, it is possible to 'export' that proposition into the CG without incurring in an inconsistency. ${ }^{13}$ In this way, Mary's attitudinal state is used to provide information to update the CG, as if Mary were a virtual participant in the conversation. Since the complement clause updates the context, it can host either the corrective or the mirative import associated with focus fronting, in compliance with the IRR.

However, this 'exportation' is not allowed when the matrix clause contains a negation, as in (10)-(11). The presence of negation implies that the proposition $p$ expressed by the complement clause is not true in all the worlds of the doxastic modal base characterized by Mary's beliefs:

${ }^{12}$ Such a discourse move aims at answering the current question under discussion (e.g., in (8), the question of who the relevant task will be assigned to): this is why the embedded proposition constitutes the 'main point of the utterance' (see Bentzen et al. 2007 and references therein).

${ }^{13}$ Consistency is an essential requirement, because an inconsistent set of propositions characterizes the empty set of possible worlds, which contains no information and allows no further update. Technically, the compatibility presupposition ensures that the doxastic modal base characterized by Mary's beliefs and the discourse CS have a non-vacuous intersection; since the embedded proposition is a superset of the modal base, it will also have a non-vacuous intersection with the CS. 
the latter includes both $p$-worlds and non- $p$-worlds, ${ }^{14}$ and it may be the case that among these, only the non- $p$-worlds are actually compatible with the CG information (i.e., only the non- $p$ worlds of the modal base are also included in the CS). In this case, if $p$ is exported into the CG, consistency is not guaranteed, and the result of the update might be the empty CS (cf. note 18). Because of the general requirement that any update must preserve consistency, the presence of negation prevents the complement clause from updating the context, and the IRR implies that the complement clause cannot host either the corrective or the mirative import associated with focus fronting.

Note, in any event, that under either view - covert raising as in (12), or licensing in the embedded left periphery - the IRR correctly predicts the distribution observed in (7)-(11). Another embedded context which disallows 'root transformations' is the complement to factive verbs. ${ }^{15}$ The ban clearly holds for Italian focus fronting under the mirative interpretation: (13) * Mi rallegro [che [una macchina] le abbiano regalato _]! refl.1SG rejoice that a car (they) her.CL have.SUBJ given The context update perspective accounts for this restriction as well. The proposition expressed by a factive complement is true in all the worlds of the discourse CS, and crucially also in all the worlds compatible with the beliefs of the matrix attitude holder (Heim 1992, 206). This means that with respect to either the CS or the doxastic modal base introduced by the matrix verb, there can be no more likely alternative than the proposition expressed by the factive complement (by

\footnotetext{
${ }^{14}$ Under a stronger 'neg-raising' interpretation, the doxastic modal base would contain only non$p$-worlds. I leave aside this interpretive option, as the weaker one is sufficient for my argument.

${ }^{15}$ See Haegeman\&Ürogdi (2010) for an analysis in terms of an intervention effect.
} 
(5)) $;^{16}$ consequently, the mirative import associated with embedded focus fronting cannot be interpreted.

As for the corrective import, the judgement is similar:

(14) A: Gianni si rammarica [che $e$ abbiano licenziato Maria].

John REFL.3SG regrets that (they) have.SUBJ fired Mary

'John regrets that they fired Mary.'

B: ?? No, si rammarica [che [Lucia] $e$ abbiano licenziato _].

No, REFL.3SG regrets that Lucy (they) have.SUBJ fired

Recall that the proposition expressed by the factive complement clause is presupposed, i.e. it is true in all the worlds of the CS. It follows that the complement clause has a vacuous update potential w.r.t. the CS: if the embedded proposition is added to the CG, the CS will remain unaltered. A vacuous update is ruled out by the Informativity condition (van Leusen 2004); hence, the factive complement lacks context update potential, and the IRR correctly predicts that its left periphery cannot host focus fronting with a corrective import. ${ }^{17}$

\footnotetext{
${ }^{16}$ Cf. note 9.
}

17 Ur Shlonsky (personal communication) asks whether all subjunctive complements are expected to disallow embedded focus fronting. Giorgi\&Pianesi (1997) propose that in Italian, subjunctive mood marks a non-realistic modal base, namely one that has a potentially vacuous intersection with the CS. With doxastic verbs, the compatibility presupposition proposed above requires that the doxastic modal base have a non-empty intersection with the CS, thus turning it into a weakly realistic modal base, which guarantees consistency if we 'export' the embedded clause proposition in the CG. Desiderative verbs instead involve the ranking of the worlds in the 


\section{Concluding remarks}

To sum up, I have argued that by the IRR (1), in Italian focus fronting is restricted to clauses that may update the discourse context, because of the specific types of import that it is associated with (either mirative or corrective). It is entirely consistent with this view that other leftperipheral structures that do not directly affect the discourse context do not fall under the IRR (for discussion see Haegeman 2004, Bianchi \& Frascarelli 2010, 2012).

At this point we can go back to our initial questions $(\S 1)$. Within the cartographic tradition, there has been a certain tension between a syntax-centered view of the functional hierarchy and a semantically oriented view. The latter gives a precise answer to the question of what determines the order that the functional categories appear in: this order can be directly determined by typedriven compositionality:

“...via their semantic types, the denotations of the features all by themselves provide the basis for a combinatorics that picks out well-formed feature sets and assigns them a hierarchical organization and a compositional denotation." (Kratzer 2009, 219; emphasis mine, VB).

At the present stage of investigation, this is still a programmatic answer, but it receives support from the detailed analysis of specific subsections of the functional spine (see e.g. the analysis of the layered DP in Zamparelli 2000, Heycock \& Zamparelli 2005).

Based on the case study of Italian focus fronting, I have likewise argued for an interface-oriented answer to the second question of whether certain phases have a more articulated left periphery

modal base by a buletic ordering source (cf. Heim 1992); the embedded proposition is not taken to be true in all the worlds of the modal base, and 'exportation' may not preserve consistency. 
than others. Following the insight of Haegeman (2004), as developed in Bianchi \& Frascarelli (2010, 2012), I have argued that root clauses (and 'quasi-subordinate' clauses) have a richer left periphery, where a specific Information Structure category (the Focus Phrase) is licensed by the presence of illocutionary Force. The crucial methodological point is that this licensing relation is not stipulated, but it follows from the specific interpretive import that the IS category is associated with.

Does this imply that semantics dictates the compositional hierarchy, and that syntactic cartography is dispensable? Personally, I don't think so. My view of the grammar maintains a central insight of Antisymmetry (Kayne 1994), namely, that the syntactic module mediates the relation between the fundamentally hierarchical semantic/conceptual structure and the fundamentally linear phonological representation (this linearity is, in turn, imposed by the temporal dimension). But the way this mediation is established is far from trivial: it involves multiple subsystems, it allows for much crosslinguistic variation, and for a different division of labor between modules from one case to the next. In the light of this empirical richness, I think a syntactician may well reverse Montague's famous sentence and conclude that after all, the best use for semantics is as a preliminary to syntax.

\section{References}

Abeillé, Anne, Godard, Danièle \& Frédéric Sabio. 2008. Two types of NP preposing in French. http://cslipublications.stanford.edu/HPSG/9/abeille-godard-sabio.pdf

Belletti, Adriana. 2004. Aspects of the low IP area. In: L. Rizzi (ed.), The structure of CP and IP, New York/Oxford: Oxford University Press. 16-51. 
Bentzen, Kristine, Gunnar Hrafn Hrafnbjargarson, Porbjörg Hróarsdóttir \& Anna-Lena Wiklund. 2007. The Tromsø guide to the force behind V2. Working Papers in Scandinavian Syntax 79. 93-118.

Bianchi, Valentina \& Mara Frascarelli. 2010. Is topic a root phenomenon? Iberia 2(1). 43-88.

Bianchi, Valentina \& Mara Frascarelli. 2012. On how to be rooted in a context. $35^{\text {th }}$ GLOW Colloquium, University of Potsdam, March 2012.

Bianchi, Valentina \& Giuliano Bocci. 2012. Should I stay or should I go? Optional focus movement in Italian. In C. Piñon (ed.), Empirical Issues In Syntax and Semantics 9. 1-18. http://www.cssp.cnrs.fr/eiss9/eiss9_bianchi-and-bocci.pdf.

Bocci, Giuliano. 2013. The syntax-prosody interface from a cartographic perspective: Evidence from Italian. Amsterdam/Philadelphia: John Benjamins.

Cruschina, Silvio. 2012. Discourse-related features and functional projections. New YorkOxford: Oxford University Press.

Dayal, Veneeta \& Jane Grimshaw. 2009. Subordination at the interface: The QuasiSubordination Hypothesis. Ms., Rutgers University.

DeLancey, Scott. 1997. Mirativity: The grammatical marking of unexpected information. Linguistic Typology 1. 33-52.

Farkas, Donka \& Kim B. Bruce. 2010. On reacting to assertions and polar questions. Journal of Semantics 27. 81-118.

Kayne, Richard S. 1994. The antisymmetry of syntax. Cambridge, MA, MIT Press.

Gärtner, Hans-Martin. 2002. On the force of V-2 declaratives. Theoretical Linguistics 28. 33-42.

Giusti, Giuliana. 2006. Parallels in clausal and nominal periphery. In M. Frascarelli (ed.), Phases of interpretation, 163-184. Berlin: Mouton de Gruyter. 
Grosz, Patrick. G. 2011. On the grammar of optative constructions. PhD thesis, MIT.

Gunlogson, Christine. 2003. True to form: Rising and falling declaratives as questions in English. New York: Routledge.

Haegeman, Liliane. 2004. Topicalization, CLLD and the left periphery. In Shaer, Benjamin, Werner Frey \& Claudia Maienborn (eds.), ZAS Papers in Linguistics 35. 157-92.

Haegeman, Liliane. 2010. The internal syntax of adverbial clauses. Lingua 120. 628-648.

Haegeman, Liliane \& Barbara Ürogdi. 2010. Referential CPs and DPs: an operator movement account. Theoretical Linguistics 32. 111-152.

Heim, Irene. 1992. Presupposition projection and the semantics of attitude verbs. Journal of Semantics 9. 183-221.

Heycock, Caroline \& Roberto Zamparelli. 2005. Friends and colleagues: Coordination, plurality, and the structure of DP. Natural Language Semantics 13. 201-270.

Hooper, Joan \& Sandra Thompson. 1973. On the applicability of root transformations. Linguistic Inquiry 4. 465-497.

Kratzer, Angelika. 1991. Modality. In Arnim von Stechow \& Dieter Wunderlich (eds.), Semantik: Ein internationales Handbuch der zeitgenössischen Forschung, 639-650. Berlin: De Gruyter.

Kratzer, Angelika. 2004. Interpreting focus: Presupposed or expressive meanings? A comment on Geurts and van der Sandt. Theoretical Linguistics 30. 123-136

Kratzer, Angelika. 2009. Making a pronoun: Fake indexicals as windows into the properties of pronouns. Linguistic Inquiry 40. 187-237.

Kratzer, Angelika. 2012. The notional category of modality. In: Modals and conditionals. New and revised perspectives. New York/Oxford: Oxford University Press. 
Leusen, Noor van. 2004. Incompatibility in context: A diagnosis of correction. Journal of Semantics 21(4). 415-442.

Miyagawa, Shigeru. 2012. Agreements that occur mainly in main clauses. In: Aelbrecht, Lobke, Liliane Haegeman and Rachel Nye (eds.), Main clause phenomena: New horizons, 79-112. Amsterdam: John Benjamins.

Meinunger, André. 2004. Verb position, verbal mood and the anchoring (potential) of sentences. In Horst Lohnstein \& Susanne Trissler (eds.), The syntax and semantics of the left periphery, 313-341. Berlin: Mouton de Gruyter.

Potts, Christopher. 2007. The expressive dimension. Theoretical Linguistics 33. 165-197.

Rizzi, Luigi. 1997. The fine structure of the left periphery. In Liliane Haegeman (ed,), Elements of grammar. Handbook in generative syntax, 281-337. Dordrecht: Kluwer.

Rooth, Mats. 1992. A theory of focus interpretation. Natural Language Semantics 1. 75-116.

Samek-Lodovici, Vieri. 2006. When right-dislocation meets the left periphery. Lingua 116. 836873.

Stalnaker, Robert. 1978. Assertion. In Peter Cole (ed.), Syntax and Semantics 9: Pragmatics, 315-332. New York: Academic Press.

Zamparelli, Roberto. 2000. Layers in the Determiner Phrase. New York: Garland.

Zimmermann, Malte 2007. Contrastive focus. In Féry, Caroline, Gisbert Fanselow, and Manfred Krifka (eds.), Interdisciplinary Studies on Information Structure 6. 147-159.

\section{Acknowledgements}

I am very grateful to Ur Shlonsky for having invited me to participate to the Geneva Workshop Syntactic cartography: Where do we go from here?. The material in $\S 2.1$. draws from recent joint work with Giuliano Bocci, and that in $\S 3$ is based on joint work with Mara Frascarelli 
(though I alone am responsible for the semantic analysis): I thank both of them. Thanks also to Silvio Cruschina, Patrick Grosz and Vieri Samek-Lodovici for making available to me their recent results and for much useful discussion. All errors are my own.

\begin{abstract}
This paper discusses focus fronting in Italian associated with two types of interpretive import: the corrective import, conveying a correction of a previous assertion, and the 'mirative' import conveying suprise or unexpectedness. It is argued that both require for their interpretation a set of focus alternatives defined at the level of the proposition, and furthermore, that both have the effect of updating (different components of) the discourse context. It is shown that, because of this update effect, Focus Fronting is restricted to root clauses and 'root-like' (discourse-active) complement clauses, which are endowed with context update potential, in compliance with the Interface Root Restriction (Bianchi\&Frascarelli 2010). This implies that the internal articulation of the clausal left periphery is sensitive to the interpretive status of the clause at the interface with the interpretive components.
\end{abstract}

Keywords: Focus fronting, Italian, correction, mirativity, root phenomena.

Total: 6140-141 (abstract + keywords) 